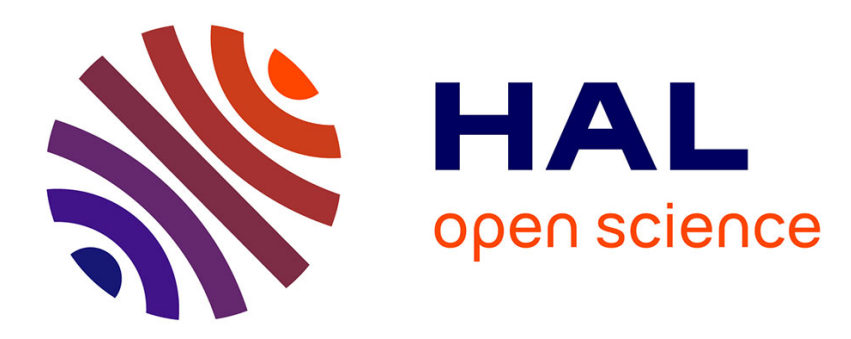

\title{
Application of diode lasers for analysis
}

C. Schnürer-Patschan, H. Groll, A. Zybin, K. Niemax

\section{- To cite this version:}

C. Schnürer-Patschan, H. Groll, A. Zybin, K. Niemax. Application of diode lasers for analysis. Journal de Physique IV Proceedings, 1994, 04 (C4), pp.C4-639-C4-642. 10.1051/jp4:19944170 . jpa-00252628

\section{HAL Id: jpa-00252628 https://hal.science/jpa-00252628}

Submitted on 1 Jan 1994

HAL is a multi-disciplinary open access archive for the deposit and dissemination of scientific research documents, whether they are published or not. The documents may come from teaching and research institutions in France or abroad, or from public or private research centers.
L'archive ouverte pluridisciplinaire HAL, est destinée au dépôt et à la diffusion de documents scientifiques de niveau recherche, publiés ou non, émanant des établissements d'enseignement et de recherche français ou étrangers, des laboratoires publics ou privés. 


\title{
Application of diode lasers for analysis
}

\author{
C. SCHNÜRER-PATSCHAN", H. GROLL ${ }^{*}$, A. ZYBIN** and K. NIEMAX ${ }^{*, * * *}$ \\ * Institut für Spektrochemie und Angewandte Spektroskipie, Dortmund, Germany \\ ** Institute of Spectroscopy, Russian Academy of Sciences, Troitzk, Russia \\ ${ }^{* * *}$ Institut für Physik, Universität Hohenheim, Stuttgart, Germany
}

\begin{abstract}
Applications of semiconductor diode lasers to element analysis by laser atomic absorption spectrometry, isotope selective Doppler-free spectroscopy and laser induced fluorescence are discussed.
\end{abstract}

Analytical laser spectroscopy has proved many times in the last 15 years that it is able to solve special, difficult analytical problems (see, for example, [1,2]). Despite the impressive results obtained in research laboratories, analytical laser spectroscopy is still not accepted and established in analytical laboratories for routine measurements. The reason for the missing acceptance are the complex, expensive and not reliable tunable dye laser systems which have been used in analytical laser spectroscopy.

However, there is a laser type which will replace the dye lasers in the short run, the semiconductor diode laser. Diode lasers are inexpensive, small, easy to operate and have long lifetimes. They are operating in $\mathrm{cw}$ mode with small line widths. Wavelength tuning is provided by temperature (slow tuning) and diode current (rapid tuning). The spectroscopic properties of diode lasers are discussed, for example, in [3-5].

Concerning element analysis, only the resonance lines of the alkali elements $\mathrm{Li}(670.8 \mathrm{~nm}), \mathrm{K}(766.5$ $\mathrm{nm}), \mathrm{Rb}(780.0 \mathrm{~nm})$ and $\mathrm{Cs}(852.1 \mathrm{~nm})$ can be excited by the fundamental radiation of commercially available laser diodes of the AlGaAs- and AlGaInP-types (wavelenght range: 620-950 nm). In addition, there are about 25 elements which can be excited from the ground state by diode lasers using weaker transitions (intercombination and quadrupole lines) [6]. If the spectrochemical source is a low-pressure plasma, strong transitions from highly populated metastable levels of non-metal atoms, such as halogenes and oxygen, can be induced by diode lasers in the red and near-ir spectral range. Fig. 1 shows such transitions in chlorine, fluorine and oxygen which allow efficient spectrometry with diode lasers.

If the power of laser diodes is of the order of $50 \mathrm{~mW}$, second harmonic generation (SHG) in nonlinear crystals can produce up to a few $\mu \mathrm{W}$ radiation power in the spectral range down to about 310 $\mathrm{nm}$. Such powers are sufficient for laser atomic absorption spectrometry (LAAS). Including SHG, the number of metal elements which can be measured by LAAS from their ground or low excited states is larger than 50 [6]. Fig. 2 shows, for example, the $396.2 \mathrm{~nm}$ absorption line of aluminium measured in an analytical flame with only $50 \mathrm{nW}$ SHG-power generated by about $30 \mathrm{~mW}$ fundamental power in a $\mathrm{LiIO}_{3}$-crystal.

LAAS with diode lasers as radiation sources has significant advantages compared with the established conventional AAS-techniques with hollow cathode lamps [7]. Since the radiation from a diode laser is tunable, the non-specific absorption background can be measured tuning the laser to the background 



Fig. 1: Strong absorption lines of $\mathrm{Cl}, \mathrm{F}$ and $\mathrm{O}$ in the near ir spectral range

Fig. 2: Absorption spectra of the Al $396.2 \mathrm{~nm}$ line measured in an analytical flame

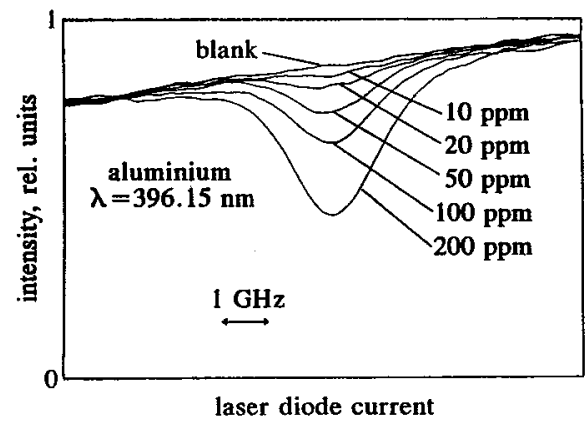

near to the absorption line. Furthermore, the dynamic range can be easily extended to higher concentrations by absorption measurement in the line wings if the line centre is optically thick. Multielement LAAS measurements are possible and have been demonstrated by simultaneous operation of six diode lasers [8]. Finally, the rapid tunability of diode lasers by current can be used for high sensitive wavelength modulation spectrometry where the low-frequency noise of the diode laser and of the spectrochemical atomizer can be significantly reduced. If the wavelength of the diode laser is sinusoidally modulated in the $\mathrm{kHz}$-range with an amplitude which corresponds approximately to the width of the absorption line, absorbances down to about $10^{-6}$ have been measured in spectrochemical sources, such as the graphite tube atomizer [9], the analytical flame [10] and a low-pressure plasma [11]. It means that the detection limits of metal elements in graphite tube atomizers and analytical flames by wavelength modulation-laser atomic absorption spectrometry (WM-LAAS) are about two orders of magnitude lower than in conventional AAS with hollow cathode lamps. For example, detection limits of $1 \mathrm{pg} / \mathrm{ml}$ and $0.5 \mathrm{ng} / \mathrm{ml}$ have been obtained for rubidium in an graphite furnace and cesium in an anlytical flame, respectively $[9,10]$. With frequency doubled diode laser radiation of about 50-100 nW and the choice of strong absorption lines, the detection limits of aluminium (graphite furnace) and chromium (analytical flame) were 0.1 and $6 \mathrm{ng} / \mathrm{ml}$, respectively $[9,10]$. Finally, it was demonstrated in $[9,10]$ that the WM-LAAS detection limits are even competitive if 
weak absorption lines in the red and near-ir spectral range are used. Detection limits of $7.5 \mathrm{ng} / \mathrm{ml}$ and $0.5 \mu \mathrm{g} / \mathrm{ml}$ were found for lanthanum (in graphite furnace) and titanium (in analytical flame), respectively.

The transitions shown in Fig. 1 have been used to measure chlorine and fluorine compounds and oxygen in a low-pressure dc plasma [11]. The molecular gases, such as $\mathrm{CCl}_{4}$ or $\mathrm{CHF}_{3}$, were introduced, for example, in a helium or argon plasma. The molecules dissociated in the plasma, and a significant fraction of chlorine and fluorine atoms was present in metastable levels which were probed by WM-LAAS. For example, Fig. 3 displays the chlorine $837.6 \mathrm{~nm}$ line measured by WM-LAAS in a low-pressure argon plasma with $10 \mathrm{ppm}$ admixture of $\mathrm{C}_{2} \mathrm{~F}_{4} \mathrm{Cl}_{2}$. The lock-in amplifier used in the measurement was operated in the second harmonic mode ( $2 \mathrm{f}$-mode). Detection limits of about 1 and $70 \mathrm{ppb}$ were found for chlorine and fluorine compounds, respectively. In very recent experiments we have coupled WM-LAAS in a low-pressure plasma with gas chromatography. First experimental results are very promising.

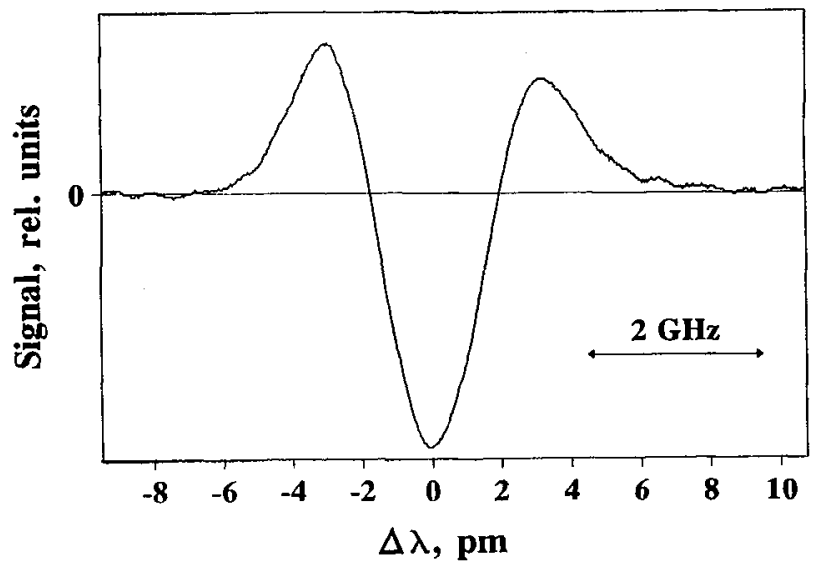

Fig. 3: $\quad 837.6 \mathrm{~nm}$ line of $\mathrm{Cl}$ measured by $2 \mathrm{f}$-mode WM-LAAS with $10 \mathrm{ppm}$ $\mathrm{C}_{2} \mathrm{~F}_{4} \mathrm{Cl}_{2}$ in a low-pressure argon discharge (from Ref. [11])

Doppler-free isotope-selective spectroscopy can be successfully applied if samples are introduced in low-pressure atomizers [6]. Saturation spectroscopy in a low-pressure graphite tube atomizer as well

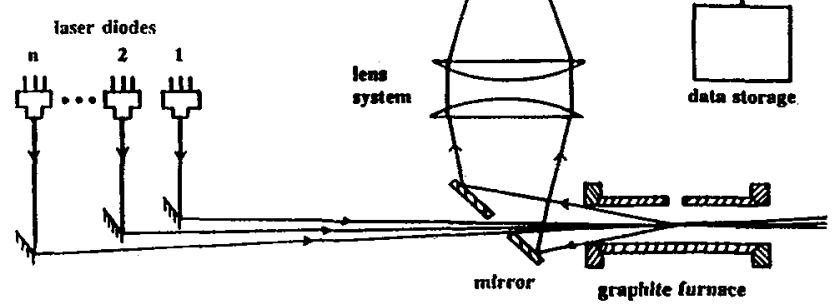

Fig. 4: Arrangement for multielement LIF in a graphite furnace (from Ref. [12]) 


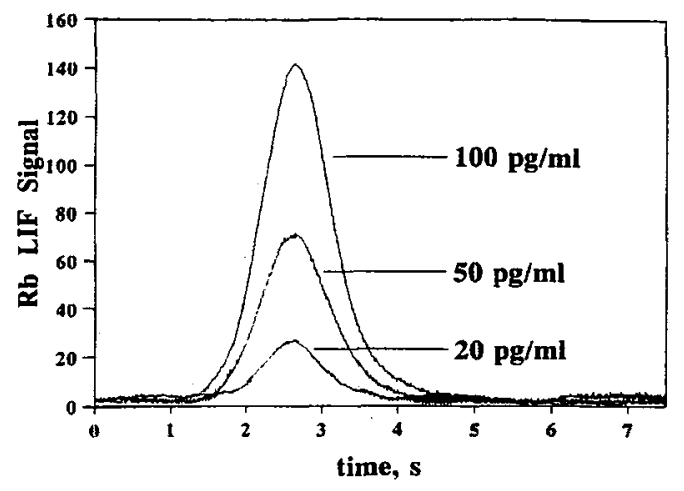

Fig. 5: LIF signals of rubidium (from Ref. [12])

as Doppler-free resonant two-photon spectroscopy in thermionic diodes and graphite tube atomizers have been demonstrated. The option to measure isotope selective is important for calibration by isotope dillution technique as applied in atomic mass spectrometry.

A simple and powerful experimental arrangement for simultaneous multielement analysis by laser induced fluorescence (LIF) with diode lasers is shown in Fig. 4. The analyte atoms are excited in a graphite tube furnace and the fluorescence is detected by a single photodiode. LIF signals of the rubidium D2 line for $10 \mu \mathrm{l}$ samples are shown in Fig. 4. LIF detection limits of 1 and $2 \mathrm{pg} / \mathrm{ml}$ for lithium and rubidium have been demonstrated, respectively [12]. These data correspond to $10 \mathrm{fg}$ of lithium and $20 \mathrm{fg}$ of rubidium in the graphite tube atomizer.

Acknowledgements - The work has been performed within the russian-german co-operation project X229.11. Financial support by Bundesministerium für Forschung und Technologie and the Ministerium für Wissenschaft und Forschung (Nordrhein-Westfalen) are gratefully acknowledged.

\section{References}

[1] V.S. Lethokov, Laser Analytical Spectrochemistry, Adam Hilger, Bristol 1986.

[2] K. Niemax, Analytical Aspects of Atomic Laser Spectrochemistry, in: Handbook of Laser Science and Technology, Eds. V.S. Letokhov, C.V. Shank, Y.R. Shen and H. Walter, Harwood, London 1989.

[3] C. Wieman and L. Hollberg, Rev.Sci.Instrum. 62 (1991) 1.

[4] R.W. Fox, C.S. Weimer, L. Hollberg and G.C. Turk, Spectrochim.Acta Rev. in press.

[5] J. Franzke, A. Schnell and K. Niemax, Spectrochim. Acta Rev. in press.

[6] K. Niemax, C. Schnürer-Patschan and H. Groll, Spectrochim. Acta Rev. in press.

[7] B. Welz, Atomic Absorption Spectrometry, Verlag Chemie, Weinheim (1985).

[8] H. Groll and K. Niemax, Spectrochim.Acta 48B (1993) 633.

[9] C. Schnürer, A. Zybin, H. Groll and K. Niemax, J.Anal.Atom.Spectrom. in press.

[10] H. Groll, Yu. Kuritsin, C. Schnürer-Patschan and K. Niemax, Spectrochim.Acta B, to be submitted.

[11] A. Zybin, C. Schnürer-Patschan and K. Niemax, Spectrochim.Acta 48B (1993) 1713.

[12] A. Zybin, C. Schnürer-Patschan and K. Niemax, Spectrochim.Acta 47B (1992) 1519. 